\title{
Asymmetric Knowledge Spillovers in a Model of Regional Innovation and Growth
}

\author{
Norman Sedgley*
}

\begin{abstract}
This paper formulates a theoretical model to investigate the determinants of the rate of innovation across economies that differ in important ways in industrial structure and face the possibility of asymmetric knowledge spillovers between industries. In particular, I wish to extend the model of expanding product variety in order to study the implications of a highly diversified sectoral composition across regional industrial bases on rates of economic innovation. A global knowledge spillover has long been recognized as a possible explanation for the absence of scale effects. What has not been appreciated is the unstable nature of the equilibrium associated with this explanation. The model can, therefore, be used to understand how, in a dynamic setting, certain regions, such as Silicon Valley or the high-tech corridor stretching along Route 28 from northern Massachusetts into southern New Hampshire, become centers of innovative activity while other regions' industries fade in importance. These results suggest a strong role for regional economics in interpreting the results of new growth theory.
\end{abstract}

\section{INTRODUCTION}

This paper formulates a theoretical model to investigate the determinants of the rate of innovation across economies that differ in important ways in industrial structure and face the possibility of asymmetric knowledge spillovers between industries. In formulating the theoretical model, I extend the general equilibrium growth framework with an expanding variety of products pioneered by Romer (1987, 1990), Aghion and Howitt (1992), and Grossman and Helpman (1991). In particular, I wish to extend the model of expanding product variety in order to highlight the implications of a highly diversified sectoral composition across regional industrial bases on rates of economic innovation.

Taking this diversification as given, what are the implications for a regional economy's rate of innovation and rate of productivity growth? What factors, if any, are likely to equalize the rate of innovation across economies that differ significantly in industrial makeup? In answering these questions, it is important to look beyond the contributions of modern growth theory and include a review of the contributions from the field of industrial organization. A large body of literature concerned with interfirm and interindustry differences in research and development and rates of innovation exists. A review of this literature, with a focus on its importance to the task at hand, is presented in section two. Many of the insights provided in this body of literature are helpful in interpreting the formal

*Department of Economics, Sellinger School of Business and Management, Loyola College, Baltimore, MD. The author thanks Bruce Elmslie, Michael Goldberg, Stanley Sedo, Ross Gittell, and two anonymous referees for helpful comments on an earlier draft of this paper. The usual caveats apply. 
model presented in section three. Section four draws some conclusions from the formal theoretical analysis.

\section{RELATED LITERATURE}

Within the field of industrial organization a large body of literature on innovation exists. This diverse literature provides both a theoretical understanding of the conditions necessary to induce firms and industries to undertake costly research and development as well as empirical studies demonstrating the important links among innovative activity within an industry, spillovers of knowledge between industries, and productivity growth. An understanding of these issues is necessary in order to formulate an idea of how the differences in industrial concentration across regions will likely lead to differences in rates of innovation across economic regions.

In contrast to the treatment of knowledge as a public good typical of the neoclassical growth framework, the literature on the nature, causes, and incentives for innovation from a more microeconomic framework focuses primarily on the role of technological opportunity and economic appropriability (Tirole 1995). The links between these views of the innovative process and economic growth are quite clear.

First, consider the role of technological opportunity. If pure research is thought of as the pursuit of basic knowledge for its own sake, then it is no surprise that this type of research is undertaken primarily in government laboratories and universities. Furthermore, the scientific ethic compels the pure scientist to share/publish the findings of his/her research with colleagues so that results can be verified and progress can continue. Pure research necessarily has many of the characteristics of the public good Solow envisioned, technological progress occurring exogenously from outside the economic system. ${ }^{1}$

Science does not progress at the same rate within all disciplines, however, and diverse industries are likely to be able to make differential use of the advances within a particular branch of science. Empirical evidence of differential opportunities for innovation is provided by Adams (1990), who uses data on industry employment of scientists by field and article count data by scientific field to investigate the links between productivity, advances in basic science, and interindustry knowledge spillovers. ${ }^{2}$

Furthermore, differential opportunities for innovation can exist if knowledge is at least partly industry specific, knowledge spillovers between industries are asymmetric, and the ease of innovation depends on cumulative experience with research and development. Rosenburg (1982) argues that domestic R\&D is necessary to take advantage of foreign ideas. Dosi (1988) suggests that cumulative experience with $R \& D$ is an important variable in explaining interindustry differences ${ }^{1}$ Dosi (1988) shows that about 80 percent of pure research is funded from sources such as the federal government, universities, and nonprofit organizations.

2Knowledge spillovers are forced to be symmetric in Adams' (1990) formulation since the spillover knowledge stocks are based on the correlation or similarity between industry employment of scientists within the specified scientific fields. 
in technological advance, while Cohen and Levinthal (1989) provide empirical evidence that cumulative experience with $R \& D$ allows firms to take better advantage of the stock of knowledge publicly available.

Empirical evidence of pervasive and significant interindustry knowledge spillovers are commonplace within the literature on innovation (Mansfield et al. 1977; Griliches 1992; Jaffe 1986; Bernstein and Ishaq 1988; Cameron 1996). These spillovers are, however, likely to be asymmetric. For example, advances in the computer and electronics industry increase innovative opportunity within the finance industry, but the significance of advances in finance are not likely to produce perfectly symmetric effects on the computer and electronics industry (see Bresnahan 1986 for a discussion of this example). While asymmetric spillovers are an empirical regularity, the consequences of asymmetric knowledge spillovers for economic growth have not been studied extensively from a theoretical perspective.

Clearly, some industries can enjoy greater opportunity for innovation due to the complex factors outlined above. In order for these opportunities to be exploited, private agents need the incentive to devote scarce resources to the risky process of innovation. Rather than dealing with pure research, it is applied research and engineering that is the focus here. This is the important phase of the innovative process, where basic ideas are used to formulate commercially viable products and processes. ${ }^{3}$

With the concept of appropriability at center stage, the relationship between market structure and the incentives for innovation becomes the topic of interest. By appropriability I mean those aspects of innovation that are moved from the category of public goods to toll goods through schemes designed to exclude those other than the innovator from using the knowledge without paying a fee. These schemes can include patent rights as well as trade secrets. Since industries differ greatly in their market structures, it is likely that they differ in their degree of appropriability. It is Schumpeter (1934) who is credited with the now widely accepted hypothesis that market power is a necessary price to pay for a dynamically innovative economy. Without the assurance of appropriating at least part of the rents from applied research and innovation, there is little incentive for entrepreneurs to invest scarce resources in such a risky venture. ${ }^{4}$

This argument is often cited as justification for the patent system within the United States, which gives the holder exclusive property rights to the innovation for a 20-year term from the patent application filing date, as per section 154 of U.S. patent law (U.S. Patent and Trademark Office 1995). Regardless of the justification for patents, intellectual property rights are an important aspect of our economy.

${ }^{3}$ A scientist or engineer employed by a private firm is tasked with finding commercial applications of more basic advances. These applications have often been dichotomized along the lines of product innovations or process innovations (Tirole 1995; Dosi 1988; Grossman and Helpman 1991; Barro and Sala-i-Martin 1995). Product innovations introduce new products to the market (either as consumer goods or intermediate goods), while process innovations typically bring down the cost of production for an existing good for the innovative firm.

${ }^{4}$ See Loury (1979) and Lee and Wilde (1980) for a formal treatment of market structure, costs, and innovation. 
Patents, however, are not the only means of appropriating the returns to R\&D. Trade secrets, lags in the dissemination of information, personal contacts, and institutional constraints on knowledge dissemination and/or applicability are also important factors. One could think of these factors as arguments in a knowledge transfer cost function. Trade secrets, patent protection, lack of tacit knowledge and experience, and geographic distance all increase knowledge transfer costs. For example, empirical evidence suggests the potential spillovers from R\&D have an important geographical component (Jaffe, Trajtenberg, and Henderson 1993; Zucker, Darby, and Armstrong 1998).

It is also true that high-technology industries tend to cluster geographically. Marshall (1920) sees three primary reasons why industries tend to cluster geographically. First, a pool of workers with skills specific to the industry is formed. Second, an intermediate-goods industry is formed to meet the needs of the primary industry. Finally, Marshall argues that knowledge flows more easily locally than across great distances. These knowledge spillovers can create local economies of scale external to the firm, giving firms with access to the local pool of knowledge a competitive advantage over more distant firms. Krugman (1991a, b) expands on Marshall's ideas, arguing that transport costs also cause geographic clusters among manufacturing industries. Patents, however, remain an important consideration in most economists' view. Tirole (1995, p. 400) states: "Still, many economists agree with Schumpeter that patents, and the concomitant static inefficiency of monopoly power, are required to give firms the proper incentive to innovate, and that patents promote dynamic efficiency."

These considerations lead Dosi (1988) to conjecture that industries form their own technological paradigms. These paradigms follow paradigms formed in basic science and typically include an exemplar and a set of heuristics. An exemplar is "an artifact to be developed" (Dosi 1988, p. 1127), such as an automobile, while a set of heuristics is a commonly accepted approach to solving problems related to the development of the exemplar. Dosi (1988, p. 1127) states: "Both scientific and technological paradigms embody an outlook, a definition of the relevant problems, a pattern of inquiry. A 'technological paradigm' defines contextually the needs that are meant to be fulfilled, the scientific principals utilized for the task, the material technology to be used. In other words, a technological paradigm can be described as a 'pattern' of solution of selected technoeconomic problems based on highly selected principals derived from the natural sciences, jointly with specific rules aimed to aquire new knowledge and safeguard it, whenever possible, against rapid diffusion to the competitors." Dosi (1988) emphasizes the development of institutions, the role of tacit knowledge, and the importance of cumulative experience with research and development.

This section has reviewed a number of theoretically compelling reasons to believe that industries are likely to differ in their propensity to innovate. It has also shown that there are important reasons to believe that the constancy of differences in industrial makeup across regions such as U.S. states is not an accident. 
Grossman and Helpman (1991, ch. 8) show how hysteresis can cause differing rates of innovation across economies, while Krugman (1991a) provides anecdotal evidence of path dependence for U.S. states. Given these considerations, it is necessary to further investigate the role of these differences in industrial structure in innovative activity. These forces could have important implications for economic growth and regional development. Are there forces in existence likely to bring about equalization in rates of innovation across regions? Perhaps knowledge spillovers across industries can bring about forces that equalize the propensity to innovate across industries and regions.

\section{A MODEL OF INTERSECTORAL DIFFERENCES IN INNOVATION AND ECONOMIC GROWTH}

This section develops a formal model of some of the salient features concerning differences in regional industrial structures, differences in industrial rates of innovation, and knowledge spillovers. I model private incentives for research and development within the framework of monopolistic competition. This model abstracts from physical capital and human capital completely. This is done both for mathematical convenience and because it allows for a focus on the roles of knowledge capital, industrial structure, and innovation in the growth process.

The model views technological innovation as occurring through the expansion of the number of consumer products available in the economy. It includes a distinct innovative sector, producing two types of knowledge. One type of knowledge is appropriable and one is not. The inappropriable output is the addition to the general stock of knowledge that occurs through research and development activities. The appropriable output involves a "blueprint." This blueprint gives the holder exclusive monopoly rights, perhaps due to a patent, to manufacture and sell the product. These profits provide the incentive for further research. Each good includes both of these aspects.

More specifically, allow for two regions $(i=A, B)$ and two industries $(k=1,2)$. Assume these regions are similar except that region $\mathrm{A}$ is completely concentrated in industry one while region two is completely concentrated in industry two. The extreme assumption that each industry is contained entirely within a given region is for analytical convenience only. This assumption should, however, allow for some insight into the role of differing industrial structures in economic growth. This concentration of industries could be due to resource differences, historical considerations, and/or institutional differences across regions. These reasons are also exogenous to the model. In other words, the model takes the existing industrial structure of each region as given and investigates the consequences of these differences for innovative activity within the region.

I begin with the consumer's problem, assuming the well-known DixitStiglitz preference structure (see Helpman and Krugman 1985, ch. 6, for an excellent discussion of the demand for differentiated products). All individuals are identical in terms of time discount rate and consumption preferences. These 
assumptions lead to the following formulation. I assume consumers maximize the present value of lifetime utility:

$$
\begin{aligned}
& \operatorname{Max}_{\mathrm{t}}=\int_{0}^{\infty} \mathrm{e}^{-\rho \tau}\left[\sigma \log C_{1}+(1-\sigma) \log C_{2}\right] \mathrm{d} \tau \\
& \mathrm{C}_{1}=\left[\int_{0}^{n_{1}} x_{1}(j)^{\alpha} d j\right]^{1 / \alpha}, C_{2}=\left[\int_{0}^{n_{2}} x_{2}(j)^{\beta} d j\right]^{1 / \beta},
\end{aligned}
$$

where $C_{k}$ is an index of consumption of goods produced in industry $k, j$ is an index of brands, $x_{k}(j)$ is the consumption of variety $j$ in industry $k$, and $n_{k}$ represents the aggregate number of brands in industry $k$ produced in the economy. Region subscripts are suppressed for notational convenience. The specification of the problem demonstrates the nature of trade between the regions. It is assumed, for simplicity, that expenditure patterns (the percentage of the total budget spent on products from each industry) are identical across regions. As will be clear when I specify a fully integrated financial sector, there is no need for trade to balance across regions. This optimization problem leads to a symmetric equilibrium where brands are imperfect substitutes. The elasticity of substitution between brands within an industry is constant and given by the following equation:

$$
\varepsilon_{1}=\frac{1}{(1-\alpha)}>1, \varepsilon_{2}=\frac{1}{(1-\beta)}>1 \text {. }
$$

that:

The optimal price index for industry $k$ is $P_{k D}=\left[\int_{0}^{n_{k}} p_{k}(j)^{1-\varepsilon_{k}} d j\right]^{\frac{1}{\left(1-\varepsilon_{k}\right)}}$ such

$$
E=P_{1 D} C_{1}+P_{2 D} C_{2}=1 \text {, }
$$

where $p_{k}(j)$ is the price of brand $j$ within industry $k$. Aggregate expenditures, $E$, are set equal to one at each point in time in choosing a numeraire. It follows that indirect utility is weakly separable in $E$ and $P_{k D}$.

A solution to the consumer's problem can be achieved in three steps. First, choose the proportion of expenditures allocated to each industry. Next, choose how to allocate those expenditures across the goods available in each industry, taking the shares across industries as given. Finally, optimize the time path of spending separately.

The first part of the problem is represented mathematically as:

$$
\operatorname{Max}\left[\sigma \log C_{1}+(1-\sigma) \log C_{2}\right] \text {, s.t. } E=P_{1 D} C_{1}+P_{2 D} C_{2} \text {. }
$$

The first order conditions are summarized as follows:

$$
C_{1}=\sigma E / P_{1 D}, C_{2}=(1-\sigma) E / P_{2 D} \text {. }
$$

Therefore, the consumer spends a constant share $\sigma$ on goods produced in industry one and a constant share $(1-\sigma)$ on goods produced in industry two. 
The second part of the consumer's problem is expressed mathematically as:

$$
\operatorname{Max}_{k}=\operatorname{Max}\left[\int_{0}^{n_{k}} x_{k}(j)^{\varphi}\right]^{1 / \varphi}, \varphi=\alpha, \beta \text {, s.t. } \Delta E=\int_{0}^{n_{k}} P_{k}(j) x_{k}(j) d j, \Delta=\sigma,(1-\sigma) .
$$

The first order conditions of this problem yield the familiar constant elasticity of substitution (CES) demand functions:

$$
x_{k}(j)=\frac{\Delta E P_{k}(j)^{-\varepsilon_{k}}}{\int_{0}^{n_{k}} P_{k}(j)^{\left(1-\varepsilon_{k}\right)} d j}
$$

The third part of the problem involves maximizing Equation 1 subject to an intertemporal budget constraint of the form:

$$
\int_{0}^{\infty} e^{-R(t)}\left[P_{1 D} C_{1}+P_{2 D} C_{2}\right] d t \leq \int_{0}^{\infty} e^{-R(t)} w(t) d t+W(0), R(t)=\int_{0}^{t} r(s) d s,
$$

where $r(t)$ is the interest rate at time $t, R(t)$ is the discount factor between time 0 and time $t, w$ is the workers wage rate, and $W(0)$ is initial wealth.

The first order conditions for these problems are:

$$
\frac{\mathrm{e}^{-\rho t} \sigma}{\mathrm{C}_{1}}=\zeta \mathrm{e}^{-\mathrm{R}(\mathrm{t})} \mathrm{P}_{1 \mathrm{D}}, \frac{\mathrm{e}^{-\mathrm{\rho t}}(1-\sigma)}{\mathrm{C}_{2}}=\zeta \mathrm{e}^{-\mathrm{R}(\mathrm{t})} \mathrm{P}_{2 \mathrm{D}} \text { ， }
$$

where $\zeta$ is the Lagrange multiplier on the budget constraint. From Equation 4 it follows that $\frac{\dot{E}}{E}=P_{1 D} C_{1}\left(\frac{\dot{C_{1}}}{C_{1}}+\frac{\dot{P_{1 D}}}{P_{1 D}}\right)+P_{2 D} C_{2}\left(\frac{\dot{C_{2}}}{C_{2}}+\frac{\dot{P}}{P_{2 D}}\right)$. The intertemporal optimization implies $\frac{\dot{C_{1}}}{C_{1}}=r(t)-\rho-\frac{\dot{P_{1 D}}}{P_{1 D}}$ and $\frac{\dot{C}_{2}}{C_{2}}=r(t)-\rho-\frac{\dot{P_{2 D}}}{P_{2 D}}$. Also note that $P_{1 D} C_{1}=\sigma$ and $\mathrm{P}_{2 \mathrm{D}} \mathrm{C}_{2}=(1-\sigma)$. Given the normalization that $\mathrm{E}=1, \frac{\dot{\mathrm{E}}}{\mathrm{E}}=0=\sigma(\mathrm{r}(\mathrm{t})-\rho)+(1-\sigma)$ $(r(t)-\rho)$. It follows from this specification that spending evolves over time such that $r(t)=\rho$.

Firms in the model are profit maximizers. It is assumed each firm produces a single brand with a production function of the form $x_{k}(j)=l_{k}(j)$. It takes one unit of labor to produce one unit of output to be sold as a final consumer good. The representative producer is faced with the problem of maximizing the following profit function:

$$
\operatorname{Max} \pi_{k}(j)=\left(p_{k}(j)-w_{k}\right) x_{k}\left(p_{i}(j)\right),
$$


where $x_{k}(j)$ is as represented in Equation 8 . This leads to each firm in industry $k$ charging the same price (since costs are the same) as given by Equation 12. Price is a constant markup over marginal costs.

(12) $\mathrm{P}_{1}=\frac{\mathrm{w}_{1}}{\alpha}, \mathrm{P}_{2}=\frac{\mathrm{W}_{2}}{\beta}$.

With expenditures set equal to unity, $E=1$, and given the symmetry of equilibrium, total profits in Region $A$ are equal to $\sigma-w_{1} X_{1}$ and total profits in region $B$ are equal to $(1-\sigma)-w_{2} X_{2}$, where $X_{k}=n_{k} x_{k}$. Using Equation 12, per firm profits in each industry are expressed as:

$$
\pi_{1}=\frac{\sigma(1-\alpha)}{n_{1}}, \pi_{2}=\frac{(1-\sigma)(1-\beta)}{n_{2}} .
$$

I now turn to the specification of technological advance, research and development, and product innovation. This model incorporates imperfect competition and models R\&D as an activity undertaken by profit-seeking entrepreneurs. The two aspects to technological advance are a blueprint giving the inventor a monopoly right to produce and sell the good and the addition to the general stock of knowledge capital in the economy, $K_{n}(k)$. Note that knowledge capital is defined separately for each industry $k$. As before, the addition to the general stock of knowledge is not appropriable by the inventor. It is assumed that the general stock of knowledge in an industry is proportional to the number of past discoveries in the industry, $n_{k}$, as well as any spillover benefits from the other industry, $\psi_{\mathrm{k}} \mathrm{n}_{\mathrm{k}^{\prime}}$. The spillover parameter, $\psi$, is interpreted as a function of the parameters that determine the cost of knowledge transfer, such as tacit knowledge, trade secret, geographic proximity, and other factors discussed previously. With the appropriate choice of units $K_{n}(1)=n_{1}+\psi_{1} n_{2}$ and $K_{n}(2)=n_{2}+\psi_{2} n_{1}, \psi_{1} \leq \psi_{2}$. This specification allows for a wide variety of assumptions concerning knowledge spillovers and public good aspects of knowledge, as is demonstrated below.

The production function for new product innovation in industry $\mathrm{k}$ is

$$
\dot{n_{k}}=L_{n k} K_{n}(k) \text {, }
$$

where $L_{n k}$ is the amount of labor employed in the innovative sector of industry $k$. The cost of inventing a new product is equal to $\frac{w_{1}}{n_{1}+\psi_{1} n_{2}}$ in region $A$ and $\frac{\mathrm{w}_{2}}{\mathrm{n}_{2}+\psi_{2} \mathrm{n}_{1}}$ in Region $B$.

Next, it is necessary to impose a capital market equilibrium condition on the model. Let $v_{k}$ denote the value of a claim to a firm's profits in industry $k$. In time $d t$, the total return to the owners of the firm is $\pi_{k}=d t+v_{k} d t$, where $\dot{v}_{k}$ is the ${ }^{5}$ The first order condition is $\varepsilon_{k}+1-\frac{w_{k}}{P_{k}(j)} \varepsilon_{k}=0 . \varepsilon_{k}$ is the price elasticity of demand. Recognizing that $\left|\varepsilon_{1}\right|=\frac{1}{(1-\alpha)}$ and $\left|\varepsilon_{2}\right|=\frac{1}{(1-\beta)}$ and solving for $P_{k}(j)$ yields Equation 12 . 
capital gain or loss experienced. This value must be equal to the return on a consumption loan of size $v_{k}, \rho v_{k} d t$. This implies

$$
\frac{\pi_{k}}{v_{k}}+\frac{\dot{v_{k}}}{v_{k}}=\rho \text {. }
$$

Since the cost of producing a blueprint is equal to $\frac{w_{k}}{n_{k}+\psi_{k} n_{k^{\prime}}}$, all resources will flow to the R\&D sector if $v_{k}>\frac{w_{k}}{n_{k}+\psi_{k} n_{k^{\prime}}}$. In order to ensure resource flows into the innovative sectors and production sectors of both industries, it is required that:

$$
(16)^{6} \frac{\mathrm{w}_{\mathrm{k}}}{\mathrm{n}_{\mathrm{k}}+\psi_{\mathrm{k}} \mathrm{n}_{\mathrm{k}^{\prime}}}=\mathrm{v}_{\mathrm{k}} \text {. }
$$

Only steady state equilibrium with positive innovation in both industries is considered. In the steady state, Equation 16 holds with equality for each industry, prices and wages are constant, and the rate of capital loss within an industry is equal to the rate of industrial innovation. This is true because profit levels are squeezed as the number of imperfect substitutes for the representative variety increases.

The dynamics of each industry can be represented by two equations, one a wage growth equation and the other a resource constraint that the industry must satisfy. Beginning with the wage growth equation, differentiate the free entry conditions, Equation 16, with respect to time. For industry one this yields:

$$
\frac{\dot{v_{1}}}{\mathrm{v}_{1}}=\frac{\dot{\mathrm{w}_{1}}}{\mathrm{w}_{1}}-\frac{\left(\dot{\mathrm{n}_{1}}+\psi_{1} \dot{\mathrm{n}_{2}}\right)}{\left(\mathrm{n}_{1}+\psi_{1} \mathrm{n}_{2}\right)}
$$

Equation 15 together with the equation for per firm profits, Equation 13, allows Equation 17 to be expressed as $\frac{\dot{w}_{1}}{w_{1}}=\rho-\frac{\sigma(1-\alpha)}{n_{1} v_{1}}+\frac{\left(\dot{n}_{1}+\psi_{1} \dot{n_{2}}\right)}{\left(n_{1}+\psi_{1} n_{2}\right)}$. Following similar arguments for industry two, the wage growth equations are:

$$
\frac{\dot{w}_{1}}{w_{1}}=\rho-\frac{\sigma(1-\alpha)}{n_{1} v_{1}}+\frac{\left(\dot{n_{1}}+\psi_{1} \dot{n}_{2}\right)}{\left(n_{1}+\psi_{1} n_{2}\right)}, \frac{\dot{w}_{2}}{w_{2}}=\rho-\frac{(1-\sigma)(1-\beta)}{n_{2} v_{2}}+\frac{\left(\dot{n_{2}}+\psi_{2}\right.}{\left(n_{1}\right)}
$$

To complete the model, the resource constraints are derived. Equation 14 together with the specification of knowledge capital, $K_{n}(k)$, implies that the ${ }^{6}$ The equality must hold whenever $\frac{\dot{n_{k}}}{n_{k}}>0$. If it did not, then all resources would be used to produce previously designed brands. 
amount of labor used in R\&D in industry one is $L_{n 1}=\frac{\dot{n_{1}}}{n_{1}+\psi_{1} n_{2}}$ and the amount of labor used in R\&D in industry two is $L_{n 2}=\frac{\dot{n}_{2}}{n_{2}+\psi_{2} n_{1}}$ The population of region i supplies $L_{i}=L_{k}$ units of labor at each moment and these services are divided between producing manufactured goods and research and development. Each firm in industry one produces and sells $\sigma / n_{1} P_{1}$ units of output and each firm in industry two produces and sells $(1-\sigma) / \mathrm{n}_{2} \mathrm{P}_{2}$ units of output. The manufacturing sector of industry one, therefore, employs $\sigma / \mathrm{P}_{1}{ }^{7}$ units of labor while the manufacturing sector of the second industry demands $(1-\sigma) / P_{2}$ units of labor. Therefore, the resource constraints for each industry are expressed as:

$$
\frac{\dot{n_{1}}}{\mathrm{n}_{1}+\psi_{1} \mathrm{n}_{2}}+\frac{\sigma \alpha}{\mathrm{w}_{1}}=\mathrm{L}_{1}, \frac{\dot{\mathrm{n}_{2}}}{\mathrm{n}_{2}+\psi_{2} \mathrm{n}_{1}}+\frac{(1-\sigma) \beta}{\mathrm{w}_{2}}=\mathrm{L}_{2},
$$

where Equation 19 makes use of the pricing equations (Equation 12). Equations 18 and 19 allow for a relatively simple graphical analysis of the determination of equilibrium rates of innovation across economies.

To simplify the algebraic manipulation, I concentrate on three important cases. Case $\mathrm{A}$ is a benchmark case in which knowledge spillovers are symmetric and complete across regions $\left(\psi_{1}=\psi_{2}=1\right)$. Case B presents the opposite extreme, in which knowledge is completely region specific $\left(\psi_{1}=\psi_{2}=0\right)$. Finally, the last case involves an asymmetry in knowledge spillovers. Here it is assumed that advances in industry one have a greater impact on the knowledge base in region two than vice versa $\left(\psi_{1} \neq \psi_{2}\right)$.

\section{Case A: The Benchmark Case $\left(\psi_{1}=\psi_{2}=1\right)$}

Consider the case in which knowledge spillovers are complete and symmetric. ${ }^{8}$ Will these assumptions allow for positive and equal rates of innovation across regions/industries? To answer this question, Equations 18 and 19 are used in a relatively simple graphical analysis. Under the assumption that $\psi_{1}=\psi_{2}=1$ and using Equation 16, the wage growth equations for industry one and industry two become:

$$
\frac{\dot{\mathrm{w}}_{1}}{\mathrm{w}_{1}}=\rho+\sum_{\mathrm{i}=1}^{2} \mathrm{~s}_{\mathrm{i}} \mathrm{g}_{\mathrm{i}}-\frac{\sigma(1-\alpha)}{\mathrm{w}_{1} \mathrm{~s}_{1}}, \frac{\dot{\mathrm{w}}_{2}}{\mathrm{w}_{2}}=\rho+\sum_{\mathrm{i}=1}^{2} \mathrm{~s}_{\mathrm{i}} \mathrm{g}_{\mathrm{i}}-\frac{(1-\sigma)(1-\beta)}{\mathrm{w}_{2} \mathrm{~s}_{2}},
$$

${ }^{7}$ Since expenditures are set equal to one and the equilibrium is symmetric, each firm sells $\sigma / n_{1} P_{1}$ units of output. Given the production function for differentiated goods, total demand for labor by this sector is $\sigma / P_{1}$. Similar arguments hold for industry two.

8I make no attempt to model differences in knowledge flows due geographical considerations versus those that are due to the peculiarities of the industries. Both considerations are implicitly included since each region specializes in one industry. 
where $n=n_{1}+n_{2}, s_{i}=n_{i} / n$ is the share of total varieties produced in industry $i$, and $g_{i}=\dot{n}_{i} / n$ is the rate of innovation in industry $i$. The resource constraints become:

$$
\mathrm{g}_{1} \mathrm{~s}_{1}+\frac{\sigma \alpha}{\mathrm{w}_{1}}=\mathrm{L}_{1}, \mathrm{~g}_{2} \mathrm{~s}_{2}+\frac{(1-\sigma) \beta}{\mathrm{w}_{2}}=\mathrm{L}_{2} .
$$

To begin, assume the regions/industries are the same in every aspect. Starting with the wage growth equations, ${ }^{9}$ Figure al shows combinations of wages and rates of innovation implying wages are constant for each industry. From Equation 20 it is clear that wages are rising above the $w_{i}=0$ schedule and falling below it. The schedule slopes downward since a lower wage, ceteris paribus, implies higher profits. This encourages a higher rate of innovation. The figure also shows the resource constraints, labeled $R_{1}$ and $R_{2}$, for industry one and industry two, respectively. An industry must, of course, always satisfy its resource constraint. The resource constraint is upward sloping because a higher rate of innovation implies a higher demand for workers in the R\&D sector and bids the wage rate upward. These constraints asymptotically approach the labor supply within their respective industry/region. ${ }^{10}$

\section{FIGURE al}

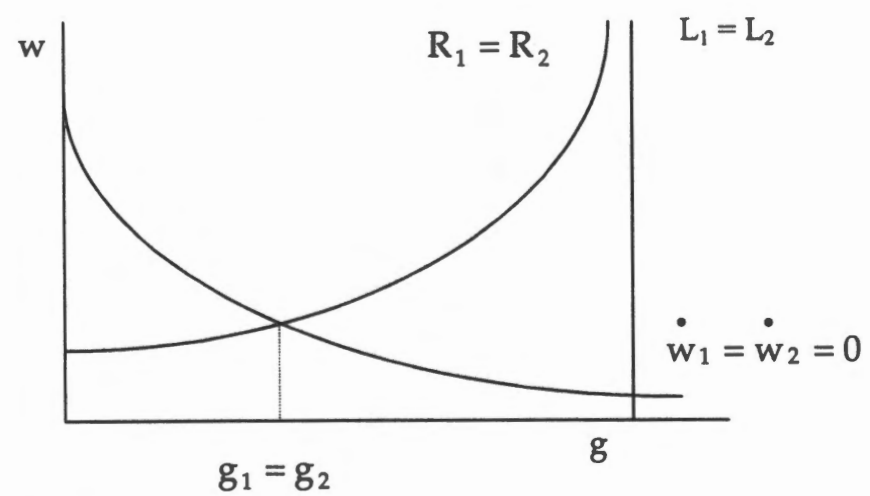

The $\dot{w}=0$ schedules and the resource constraints coincide because the regions/industries are the same. Given the arguments outlined above, each regional economy must be producing at the intersection of its resource constraint The slopes of the $\dot{w}=0$ schedule for industries one and two are $\frac{-w_{1}^{2} s_{1}^{2}}{\sigma(1-\alpha)}$ and $\frac{-w_{2}^{2} s_{2}^{2}}{(1-\sigma)(1-\beta)}$, respectively. The intercepts are $\frac{\sigma(1-\alpha)}{s_{1}\left(p+s_{2} g_{2}\right)}$ and $\frac{(1-\sigma)(1-\beta)}{s_{2}\left(p+s_{1} g_{1}\right)}$.

10The slopes of the $R_{k}$ schedule for industries one and two are $\frac{w_{1}^{2} s_{1}}{\sigma \alpha}$ and $\frac{w_{2}^{2} s_{2}}{(1-\sigma)_{\beta}}$, respectively. The intercepts are $\frac{\sigma \alpha}{L_{1}}$ and $\frac{(1-\sigma) \beta}{L_{2}}$. 
and its $\dot{w}=0$ schedule. Therefore, under the assumptions that each industry is identical, a steady state (where $\mathrm{g}_{1}, \mathrm{~g}_{2}, \mathrm{w}_{1}$, and $\mathrm{w}_{2}$ are constant) exists where the share of total varieties produced in industry $i, s_{i}$, is constant and the rates of innovation are equal across the two industries $\left(g_{1}=g_{2}\right.$ is necessary if $s_{1}$ and $s_{2}$ remain constant).

What if the two regional economies are not identical? A myriad of possibilities for analysis exists. The preference parameters, for example, can be allowed to vary across the industries. This amounts to differences in market structures and appropriability. I will focus, however, on regions differing in the size of their labor forces, since there is so much discussion of scale effects in the economic growth literature. What if state $\mathrm{B}$ is larger (in terms of $\mathrm{L}$ ) so that industry two has a more relaxed resource constraint? Figure a2 demonstrates the case in which $L_{2}>L_{1}$. A razor's edge equilibrium exists where the share of total varieties produced in industry $i, s_{i}$, is constant since the rates of innovation are equal across the two industries.

Given that the industries differ only in terms of resources, the intersection implies that the steady state is one where industry two produces a larger number of brands than industry one $\left(s_{2}>s_{1}\right)$. More brands in industry two imply lower profits and a lower incentive to innovate. This offsets the resource advantage of the industry.

\section{FIGURE a2}

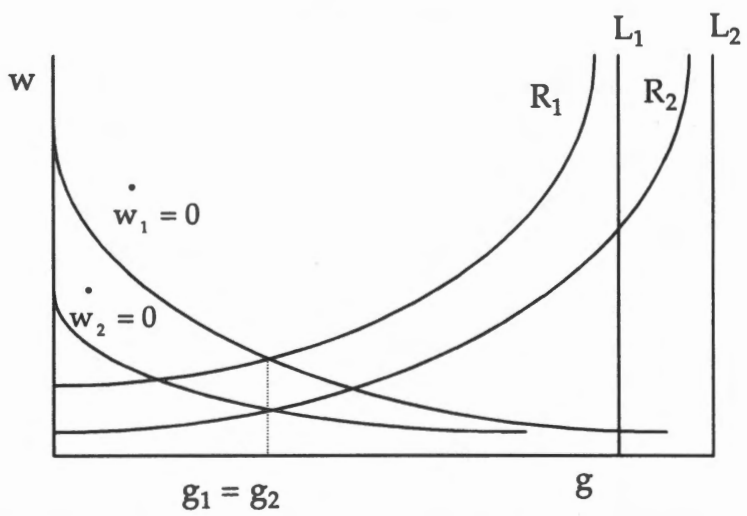

Is the equilibrium defined in Figure a2 the only possible outcome? Suppose the intersection of the $R_{2}$ and the $w_{2}=0$ schedules lies to the right of the intersection of the $R_{1}$ and $\dot{w}_{1}=0$ schedules, implying $g_{2}>g_{1}$. This would be the case if, starting from Figure a1, the labor supply for industry two were allowed to increase. Since $\mathrm{n}_{2}$ and $\mathrm{s}_{2}$ cannot change instantaneously, $\dot{\mathrm{w}}_{1}=0$ continues to be the relevant schedule for both industries. This implies $g_{2}>g_{1}$. A higher $g_{2}$ has an instantaneous impact on industry one through a higher rate of capital loss, since future prospects have changed in favor of more new brands in the future. This 
effect occurs because knowledge spillovers from industry two lower the cost of innovation in industry one, and more future competition implies lower future profits.

The wage growth equation for industry one (see Equation 20) can be expressed as $\rho=\left[-\left(s_{1} g_{1}+s_{2} g_{2}\right)\right]+\frac{\sigma(1-\alpha)}{s_{1} w_{1}}$ where I have used the fact that $\dot{w}=0$, since the economy always operates at a point of intersection between the resource constraint and the $\dot{w}=0$ schedule. The term in square brackets represents the rate of equilibrium capital loss due to new entry and the last term represents the dividend yield from ownership of a firm in the industry. Since $\rho$ is constant, no one will wish to hold shares of stock in a firm operating in this industry unless this industry offers a lower wage at any given rate of innovation, $\mathrm{g}_{1}$. This implies a downward shift in the $\dot{\mathrm{w}}_{1}=0$ schedule, and an associated movement to the left on the $R_{1}$ schedule. The rate of innovation in industry one falls, and the fall in $g_{1}$ has the opposite impact on industry two.

The economy moves closer to the situation depicted in Figure a3, in which $\mathrm{g}_{1}$ is zero, $\mathrm{g}_{2}$ is constant, and all the labor in industry one is employed in producing previously developed goods. Once $g_{1}$ falls to zero, the assumptions used to construct the loci for industry one no longer hold. Therefore, the equilibrium represented in Figure a2 is the only possible equilibrium in which both industries innovate.

\section{FIGURE a3}

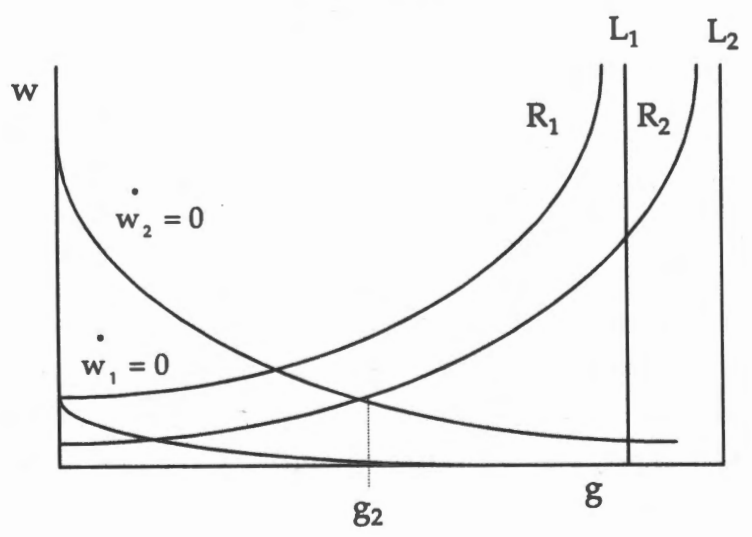

Consider a two-region model in which all industries innovate and knowledge spillovers are symmetric across industries and available in both regions. In this case, the scale effects implied by a one-region model of endogenous growth 
are eliminated. Thus, the formulation of knowledge spillovers provides an alternative explanation of why scale effects, suggested in many endogenous growth models, do not appear to exist in actual economies. What if these assumptions are relaxed?

\section{Case B: Knowledge is Industry Specific $\left(\psi_{1}=\psi_{2}=0\right)$}

Next, consider the case in which knowledge spillovers do not exist. Knowledge in this case is industry specific, and advances in one industry have no effect on the cost of introducing new products in the other industry. Under the assumption that $\psi_{1}=\psi_{2}=0$, the wage growth equations for industry one and industry two simplify to:

$$
\frac{\dot{\mathrm{w}}_{1}}{\mathrm{w}_{1}}=\rho-\frac{\sigma(1-\alpha)}{\mathrm{w}_{1}}+\mathrm{g}_{1}, \frac{\dot{\mathrm{w}}_{2}}{\mathrm{w}_{2}}=\rho-\frac{(1-\sigma)(1-\beta)}{\mathrm{w}_{2}}+\mathrm{g}_{2} ，
$$

where $g_{i}=\dot{n}_{i} / n$ is the rate of innovation in industry $i$. The resource constraints become:

$$
\mathrm{g}_{1}+\frac{\sigma \alpha}{\mathrm{w}_{1}}=\mathrm{L}_{1}, \mathrm{~g}_{2}+\frac{(1-\sigma) \beta}{\mathrm{w}_{2}}=\mathrm{L}_{2} .
$$

The interpretations of the schedules are the same as before, except now the industries develop independent of one another. Figure b1 shows combinations of wages and rates of innovation such that wages are constant as well as resource constraints. ${ }^{11}$

The reader can verify that scale effects are implied in this specification. For the sake of variety, Figure b1 is drawn under the assumption that $\alpha<\beta$ and $g_{1}>g_{2}$. In other words, demand is more inelastic in industry one than in industry two. Once again, each regional economy is producing at the intersection of its resource constraint and its $\mathbf{w}=0$ schedule. It is clear from the diagram that a steady state exists in which rates of innovation are constant for each regional economy and industry. Schumpeter would not be surprised to see that innovation is higher in the region where the industrial base enjoys more market power and a higher markup over marginal costs. This market power could come from a number of sources, including patent protection and natural barriers to entry, such as strong scale economies.

There is no reason to expect rates of innovation to be equal across industries and economies when knowledge is industry specific, unless it is a circumstance of pure coincidence. Rates of innovation are going to differ across regions and industries if knowledge is industry specific. This specification of knowledge

${ }^{11}$ The slopes of the $R_{k}$ schedule for industries one and two become $\frac{w_{1}^{2}}{\sigma \alpha}$ and $\frac{w_{2}^{2}}{(1-\sigma) \beta}$, respectively. The intercepts are $\frac{\sigma \alpha}{L_{1}}$ and $\frac{(1-\sigma) \beta}{L_{2}}$. 
spillovers produces two dynamically independent economies, each identical to the economy outlined in Grossman and Helpman (1991). Furthermore, if knowledge is industry and/or geographically specific, then the model suggests scale effects.

\section{FIGURE b1}

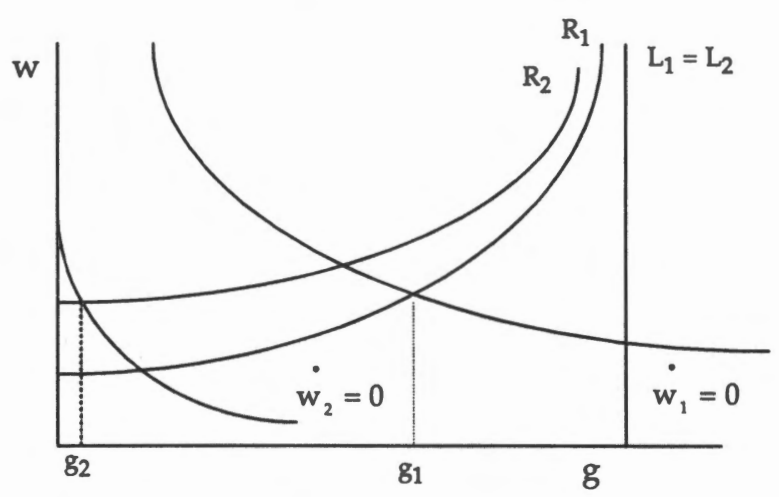

\section{Case C: Asymmetric Knowledge Spillovers $\left(\psi_{1} \neq \psi_{2}\right)$}

Finally, consider the case in which knowledge spillovers are asymmetric. This case conforms most closely with the empirical regularities cited in section two of this paper. Not surprisingly, it is also the most complicated case considered. Knowledge in this case is not entirely industry specific, and advances in one industry have some impact on other industries. Advances in one's home industry add to the knowledge base in the home industry, but also add some useful knowledge for innovation in other industries. The other side of the coin is that the home industry can benefit from technological advances in other industries. These benefits may be less than, equal to, or greater than the benefits other industries enjoy due to research in the home industry. ${ }^{12}$

Under the assumption that $\psi_{1} \neq \psi_{2}$, the wage growth equations for industry one and industry two are:

12The slopes of the $\dot{w}=0$ schedule for industries one and two are now equal to $\frac{-w_{1}^{2}\left(\frac{n_{1}}{n_{1}+\psi_{1} n_{2}}\right)^{2}}{\sigma(1-\alpha)}$ and
$-\frac{w_{2}^{2}\left(\frac{n_{2}}{n_{2}+\psi_{2} n_{1}}\right)^{2}}{(1-\sigma)(1-\beta)}$, respectively. The intercepts are $\frac{\sigma(1-\alpha)}{\left(\frac{n_{1}}{n_{1}+\Psi_{1} n_{2}}\right)\left(\rho+g_{2}\left(\frac{n_{2} \Psi_{1}}{n_{1}+\Psi_{1} n_{2}}\right)\right)}$ and $\frac{(1-\sigma)(1-\beta)}{\left(\frac{n_{2}}{n_{2}+\Psi_{2} n_{1}}\right)\left(\rho+g_{1}\left(\frac{n_{1} \Psi_{2}}{n_{2}+\Psi_{2} n_{1}}\right)\right)}$. 
(24)

$$
\begin{aligned}
& \frac{\dot{w}_{1}}{w_{1}}=\rho-\frac{\sigma(1-\alpha)}{w_{1}\left(\frac{n_{1}}{n_{1}+\psi_{1} n_{2}}\right)}+g_{1} \frac{n_{1}}{n_{1}+\psi_{1} n_{2}}+g_{2} \frac{n_{2} \psi_{1}}{n_{1}+\psi_{1} n_{2}}, \\
& \frac{\dot{w}_{2}}{w_{2}}=\rho-\frac{(1-\sigma)(1-\beta)}{w_{2}\left(\frac{n_{2}}{n_{2}+\Psi_{2} n_{1}}\right)}+g_{2} \frac{n_{2}}{n_{2}+\psi_{2} n_{1}}+g_{1} \frac{n_{1} \psi_{2}}{n_{2}+\psi_{2} n_{1}} .
\end{aligned}
$$

The resource constraints ${ }^{13}$ become:

$$
\mathrm{g}_{1} \frac{\mathrm{n}_{1}}{\mathrm{n}_{1}+\psi_{1} \mathrm{n}_{2}}+\frac{\sigma \alpha}{\mathrm{w}_{1}}=\mathrm{L}_{1}, \mathrm{~g}_{2} \frac{\mathrm{n}_{2}}{\mathrm{n}_{2}+\psi_{2} \mathrm{n}_{1}}+\frac{(1-\sigma) \beta}{\mathrm{w}_{2}}=L_{2} .
$$

Assume each economy differs only in terms of knowledge spillovers. Each industry/economy must be producing at the intersection of its resource constraint and its $\dot{\mathrm{w}}=0$ schedule at each point in time. In this case, it is possible to find steady state equilibrium with innovation in both industries. Again, the necessary conditions require specific assumptions concerning the number of previously produced brands within each industry. Mathematically, we seek equilibrium where $\frac{n_{K}}{n_{K}+\psi_{i} n_{K^{\prime}}}$, the proportion of knowledge capital in industry $K$ produced in industry $K$, is constant. This occurs when the growth rates of $n_{1}$ and $n_{2}$ are equal.

\section{FIGURE c1}

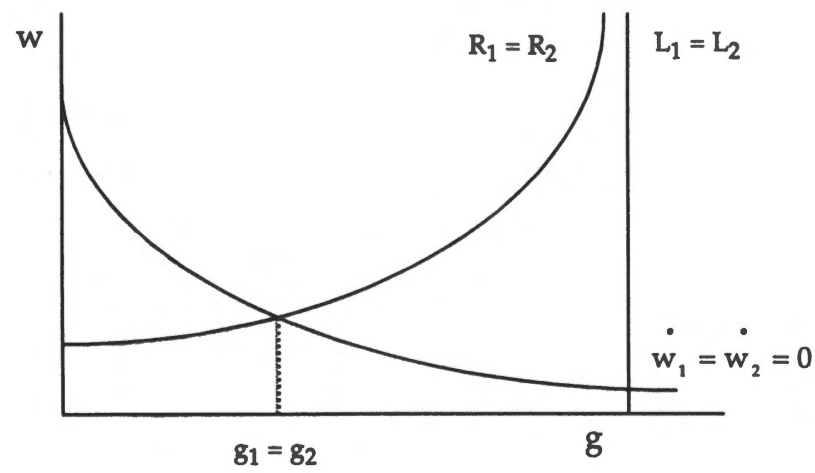

${ }^{13}$ The slopes of the $R_{k}$ schedule for industries one and two become $\frac{\left(\frac{n_{1}}{n_{1}+\psi_{1} n_{2}}\right) w_{1}^{2}}{\sigma \alpha}$ and $\frac{\left(\frac{n_{2}}{n_{2}+\psi_{2} n_{1}}\right) w_{2}^{2}}{(1-\sigma) \beta}$,
respectively. The intercepts are $\frac{\sigma \alpha}{L_{1}}$ and $\frac{(1-\sigma) \beta}{L_{2}}$. 
Refer to Figure c1. The assumption needed to obtain steady state equilibrium with equal and positive rates of innovation is that the number of brands produced within industry one (the industry enjoying fewer spillover-related benefits) is lower than the number of previously invented brands in industry two. Under these conditions, it is possible to obtain values of $n_{1}$ and $n_{2}$ such that the wage change equations and resource constraints coincide. The economic intuition is clear. A lower $n_{1}$ means less competition among brands in industry one, while a higher $n_{2}$ is required to produce more competition within industry two. Less competition in industry one relative to industry two implies higher profits relative to industry two. These higher profits are just high enough to create an incentive for innovation in industry one, which makes up for the lower benefits from the external knowledge spillovers from the other industry.

Once again, however, the equilibrium is an unstable razor's edge equilibrium. Any exogenous change in the model will bring about the same dynamic adjustments experienced in the benchmark case (case A).

As with the first case, scale effects will not be present if both economies innovate. The reasoning is the same, except that the number of brands by which the industry in the larger economy must exceed the number of brands in the smaller economy depends on the degree of spillovers. Greater spillover benefits from the larger industry to the smaller industry, for example, imply that a smaller difference in the number of brands between the industries is necessary to eliminate the advantage in incentives to innovate new product lines that a larger economy enjoys from a more relaxed resource constraint. In general, the difference in the size of the industries will be a decreasing function of the degree of knowledge spillovers.

In general, economic theory seems to suggest that differing industrial structures might cause differing rates of innovation and technological advance, even across regions that "share a common central government and therefore have similar institutional setups and legal systems"(Barro and Sala-i-Martin 1995, p. 382). This is true if knowledge is specific to industries or is geographically concentrated.

This model is motivated by important trends and facts concerning regional development and growth. Economic regions are characterized by industrial concentrations and these concentrations are slow to change (Krugman 1991a). Furthermore, different regions have different propensities to innovate and it is expected that this is related to industrial concentration. If a standard Grossman and Helpman model of innovation is opened to differential knowledge spillovers, then these trends together with the apparent lack of scale effects in the economic growth literature can be easily understood.

An empirical test of the model is left to future research, but it is worth discussing what such a test might look like. It would be most useful to look to MSA data in a standard growth framework as explored by Glaeser, Scheinkman, and Shleifer (1995). Scale effects in terms of city size can be re-estimated in light of asymmetric knowledge spillovers. The difficulty, naturally, is in measuring 
knowledge and the degree to which it spills over across borders. The work of Jaffe, Trajtenberg, and Henderson (1993) can provide a guide. Using data on patent citations from outside an MSA, an index of MSA knowledge spillovers can be calculated and included in a standard growth framework. The model suggests that a measure of city size such as population or population density would be positive and significant after controlling for these informational spillovers.

\section{CONCLUSION}

In this paper I provide a formal model to investigate the interregional relationships among the public good aspects of knowledge, symmetry and asymmetry of knowledge spillovers, rates of industrial innovation, differing degrees of market power, resource constraints, and economic growth. Such a formulation is likely to be of interest to researchers in many fields.

As with all models, the implications of the formulation provided here should be interpreted with care. One potentially important aspect, I believe, is not accounted for. Labor mobility is not allowed across the regions in the model. The migration of labor, to take advantage of jobs in high-wage industries, will likely introduce forces that cause rates of innovation to equalize. As a first approximation, the model is still useful. The Census Bureau reports that, between March 1995 and March 1996, only 15 percent of the 43 million movers crossed state lines, and 62.8 percent made a move within the same county (U.S. Bureau of the Census 1997). Furthermore, Barro and Sala-i-Martin $(1991,1995)$ report that migration is not an important variable in explaining economic growth across U.S. states. These findings are echoed by Glaeser, Scheinkman, and Shleifer (1995), who find no evidence that migration accounts for wage convergence across U.S. cities and SMSAs over the period 1960 to 1990.

The most important lesson learned is simply that very complex interactions between firms and industries have important implications for rates of innovation and perhaps, therefore, for economic growth across otherwise similar regions. Empirical puzzles including the absence of scale effects in economic growth can be understood by allowing for asymmetric knowledge spillovers and regional differences in industrial concentration. While many growth theorists would not be surprised that the conclusion of no scale effects can be supported with some form of global knowledge spillovers, most would be surprised at the demonstrated unstable nature of the equilibrium associated with such explanations. The model can be used to understand how, in a dynamic setting, certain regions, such as Silicon Valley or the high-tech corridor stretching along Route 28 from northern Massachusetts into southern New Hampshire, become centers of innovative activity while other regions' industries fade in importance. These results suggest a strong role for regional economics in interpreting the results of new growth theory. 


\section{REFERENCES}

Adams, James. "Fundamental Stocks of Knowledge and Productivity Growth." Journal of Political Economy 98 (4) (1990), 673-701.

Aghion, Philippe, and Peter Howitt. "A Model of Growth through Creative Destruction." Econometrica 60 (2) (1992), 323-351.

Barro, R., and X. Sala-i-Martin. "Convergence Across States and Regions" Brookings Papers on Economic Activity 1 (1991), 107-182.

. Economic Growth. New York: McGraw-Hill, 1995.

Bernstein, Jeffery, and Nadiri Ishaq. "Interindustry R\&D Spillovers, Rates of Return, and Production in High Technology Industries." American Economic Review Papers and Proceedings 78 (1988), 429-434.

Bresnahan, Timothy. "Measuring the Spillovers from Technical Advance: Mainframe Computers in Financial Services." American Economic Review 76 (1986), 742-755.

Cameron, Gavin. "Innovation and Economic Growth." Centre for Economic Performance Discussion Paper No. 277. London, 1996.

Cohen, Wesley, and Daniel Levinthal. "Innovation and Learning: The Two Faces of R\&D." Economic Journal 99 (1989), 569-596.

Dosi, Giovanni. "Sources, Procedures, and Microeconomic Effects of Innovation." Journal of Economic Literature 26 (1988), 1120-1171.

Glaeser, Edward, José Scheinkman, and Andrei Shleifer. "Economic Growth in a Cross Section of Cities." Journal of Monetary Economics 36 (1995), 117-143.

Griliches, Zvi. "The Search for R\&D Spillovers." NBER Working Paper No. 3768. Cambridge, Mass., 1992.

Grossman, Gene, and Elhanan Helpman. Innovation and Growth in the Global Economy. Cambridge: MIT Press, 1991.

Helpman, Elhanan, and Paul Krugman. Market Structure and Foreign Trade. Cambridge: MIT Press, 1985.

Jaffe, Adam. "Technological Opportunity and Spillovers of R\&D: Evidence from Firms' Patents, Profits, and Market Value." American Economic Review 76 (1986), 984-100.

Jaffe, Adam, Manuel Trajtenberg, and Rebecca Henderson. "Geographic Localization of Knowledge Spillovers as Evidenced by Patent Citations." Quarterly Journal of Economics 108 (1993), 577-598.

Krugman, Paul. Geography and Trade. Cambridge: MIT Press, 1991a. . "Increasing Returns and Economic Geography." Journal of Political Economy 99 (3) (1991b), 483-499.

Lee, Tom, and Louis Wilde. "Market Structure and Innovation: A Reformulation." Quarterly Journal of Economics 94 (1980), 429-436.

Loury, Glenn. "Market Structure and Innovation." Quarterly Journal of Economics 93 (1979), 395-410. 
Mansfield, Edwin, John Rapoport, Anthony Romeo, Samuel Wagner, and George Beardsley. "Social and Private Rates of Return from Industrial Innovation." Quarterly Journal of Economics 91 (1977), 221-240.

Marshall, Alfred. Principals of Economics. London: Macmillan Publishers, 1920.

Romer, Paul. "Growth Based on Increasing Returns Due to Specialization." American Economic Review 77 (2) (1987), 56-62.

. "Endogenous Technological Change." Journal of Political Economy 98 (1990), S71-S102.

Rosenberg, Nathan. Inside the Black Box: Technology and Economics. Cambridge: Cambridge University Press, 1982.

Schumpeter, Joseph. The Theory of Economic Development. Cambridge: Harvard University Press, 1934.

Tirole, Jean. The Theory of Industrial Organization. Cambridge: MIT Press, 1995.

U.S. Bureau of the Census. Current Population Reports: Geographic Mobility: March 1995 to March 1996. Washington, D.C., 1997.

U.S. Patent and Trademark Office. Setting the Course for Our Future: A Patent and Trademark Office Review. Washington, D.C., 1995.

Zucker, Lynne, Michael Darby, and Jeff Armstrong. "Geographically Localized Knowledge: Spillovers or Markets?" Economic Inquiry 36 (1998), 65-86. 